\title{
Effectiveness of training intervention to improve medical student's information literacy skills
}

\author{
Mohammadhiwa Abdekhodaa, ${ }^{1,2}$ Afsaneh Dehnad ${ }^{3}$ and Mahmood Yousefi ${ }^{4}$ \\ ${ }^{1}$ Department of Medical Library and Information Sciences, ${ }^{2}$ Iranian Center of Excellence in Health Management, \\ School of Health Management and Medical Informatics, Tabriz University of Medical Sciences, Tabriz, ${ }^{3}$ Department \\ of Foreign Language, School of Health Management and Information Sciences, Iran University of Medical Sciences, \\ Tehran, and ${ }^{4}$ Department of Management and Health Services, School of Health Management and Medical \\ Informatics, Tabriz University of Medical Sciences, Tabriz, Iran
}

This study aimed to assess the efficiency of delivering a 4-month course of "effective literature search" among medical postgraduate students for improving information literacy skills. This was a cross-sectional study in which 90 postgraduate students were randomly selected and participated in 12 training sessions. Effective search strategies were presented and the students' attitude and competency concerning online search were measured by a pre- and post-questionnaires and skill tests. Data were analyzed by SPSS version 16 using t-test. There was a significant improvement $(p=0.00)$, in student's attitude. The mean (standard deviation [SD]) was 2.9 (0.8) before intervention versus the mean (SD) 3.9 (0.7) after intervention. Students' familiarity with medical resources and databases improved significantly. The data showed a significant increase $(p=0.03)$, in students' competency score concerning search strategy design and conducting a search. The mean (SD) was 2.04 (0.7) before intervention versus the mean (SD) 3.07 (0.8) after intervention. Also, students' ability in applying search and meta search engine improved significantly. This study clearly acknowledges that the training intervention provides considerable opportunity to improve medical student's information literacy skills.

Key Words: Education, Online search, Information literacy, Medical students, Health services

\section{Introduction}

Search skills and strategies play an important role in locating relevant information since the emergence of evidence-based medicine (EBM) by health care staff; however, there are many medical students graduating from medical schools without acquiring these skills which are crucial in their career lives [1,2].

Recently, "medical information systems" course has been integrated into the curriculum of medical educa- tion, and is often perceived as a prerequisite of learning about the practice of EBM. Several research studies have been applied in several studies to survey the impact of training intervention on students' skills in online search [3].

However, there is a small, but growing research on identifying what is the best practice in educating students and clinicians to conduct effective search. For example, Ghali et al. [4] carried out a before and after study by teaching mini courses in EBM for medical students in four sessions focusing on writing clinical
Received: July 5, 2016 • Revised: September 13, 2016 • Accepted: October 17, 2016 Corresponding Author: Afsaneh Dehnad (http://orcid.org/0000-0001-9874-3045)

Department of Foreign Language, School of Health Management and Information Sciences, Iran University of Medical Sciences, Valiaser ave. Rashid yasemi ave., Iran

Tel: +98-04133251378 Fax: +98-04133251378 email: afsanehdehnad@gmail.com
Korean J Med Educ 2016 Dec; 28(4): 391-395.

https://doi.org/10.3946/kjme.2016.44

eISSN: 2005-7288

(C) The Korean Society of Medical Education. All rights reserved. This is an open-access article distributed under the terms of the Creative Commons Attribution Non-Commercial License (http:// creativecommons.org/licenses/by-nc/3.0/), which permits unrestricted non-commercial use, distribution, and reproduction in any medium, provided the original work is properly cited. 
questions, searching Medline, having critical appraisal, and applying evidence. The results of this study showed significant improvement in students' search skills in the four aforementioned areas [4].

This study aimed to assess the efficiency of delivering a 4-month course of "effective literature search" among medical postgraduate students for improving their attitudes and skills regarding online literature search.

\section{Subjects and methods}

This was a cross-sectional study administrated in October 2015 and January 2016 subsequently. This prepost design was intended to assess the effect of onesemester training intervention of "effective literature search" among medical postgraduate students of Tabriz University of Medical Sciences.

The participants in this study were postgraduate students who participated in 4-month course of "effec- tive literature search." As for the sample, from 197 postgraduate students ( $\mathrm{n}=197), 90$ students were selected by stratified randomized sampling scheme, with stratification for master of science (MSc) students (65\%), and doctor of philosophy $(\mathrm{PhD})$ students $(35 \%)$.

In October 2015, before the training begins, students' perception toward online search, and their search skills were assessed by a researcher-made questioners and on the basis of a literature review. The survey included structured questionnaire in four areas addressing in prior paragraph. "Totally agree," "agree," "neutral," "disagree," and "totally disagree," formed the questionnaire which was based on a 5-point Likert scale.

Five faculty members of medical education department confirmed the content and face validity of the study instrument. Cronbach's $\alpha$ coefficient revealed a high degree of internal consistency (0.9). Also, the reliability of the questionnaire was measured by test-retest (0.9).

Participants took part in 12 training sessions, in which familiarity with medical resources and databases, design

Table 1. Demographic Details of the Students Participated in the Present Study

\begin{tabular}{lcl}
\hline \multicolumn{1}{c}{ Component } & Item no. & Item \\
\hline $\begin{array}{l}\text { Attitude toward } \\
\text { online literature }\end{array}$ & 1 & Search and retrieval of information is often difficult and a burden to me. \\
searching & 2 & I have the skills necessary for searching and finding relevant information. \\
& 4 & Most of the time, I am successful in searching and finding relevant information in my field of study. \\
& 6 & Finding articles and scientific information from the internet and databases requires certain skills and \\
expertise.
\end{tabular}


search strategy and conduct a search, and applying search and meta search engine, were presented by highly qualified teacher (HQT).

In January 2016, after a 4-month course of "medical information systems," students' perception and their search skills were reassessed. Participants took part in a practice test that was conducted by HQT. In practice test, the students' information literacy competency in designing search strategy, formulating search questions, finding keywords, applying Boolean logic and using other search functions such as search filtering and transaction were assessed.

All data from pre- and post-survey were entered in SPSS software using a t-test to compare score changes in four areas form before intervention versus after inter- vention. Table 1 shows the questions used in the survey measuring the various components of the study.

Demographic information of the study showed that the majority of the participants (70.2\%) were female (Table 2). More than 45 percent of participants were in the age range of 25 to 30 with the mean age of 27.3. The data also showed more than 64 percent of students had MSc. Table 3 shows that there was a significant change in students' attitude which improved considerably toward online literature search after the training. The data from Table 3 also showed students' familiarity with medical resources and databases as well as their ability to apply search strategies and skills improved significantly. Likewise, there was a significant change in students' ability to apply search and meta search engines.

Table 2. Demographic Information of the Participants

\begin{tabular}{clcccc}
\hline Demographic & Category & Frequency & Percent & Mean & Standard deviation \\
\hline Gender & Male & 10 & 11.11 & & \\
& Female & 78 & 86.60 & & \\
& Missing & 2 & 2.20 & & \\
Age (yr) & Total & 90 & 100 & & \\
& $22-25$ & 16 & 17.77 & 27.8 & \\
& $25-30$ & 54 & 60 & & \\
& $30-35$ & 13 & 14.44 & \\
Grade & Missing & 7 & 7.70 & \\
& Total & 90 & 100 & \\
& MSc & 58 & 64.40 & \\
& PhD & 32 & 35.50 & & \\
& Missing & 0 & 0 & \\
& Total & 90 & 100 & \\
\hline
\end{tabular}

MSc: Master of sciences, PhD: Doctor of philosophy.

Table 3. Students Competency Score across Online Literature Searching before and after Intervention

\begin{tabular}{|c|c|c|c|c|c|c|c|}
\hline \multirow{2}{*}{ Component } & \multicolumn{2}{|c|}{ Before intervention } & \multicolumn{2}{|c|}{ After intervention } & \multicolumn{2}{|c|}{ Paired samples test } & \multirow{2}{*}{ Result } \\
\hline & Mean & SD & Mean & SD & $\mathrm{t}$ & $\mathrm{p}$-value & \\
\hline Attitude toward online literature searching & 2.90 & 0.85 & 3.92 & 0.7 & -9.24 & 0.00 & Significant \\
\hline Familiarity with medical resources and databases & 3.01 & 0.93 & 4.02 & 0.9 & -8.39 & 0.00 & Significant \\
\hline Ability to design search strategy and conduct a search & 2.04 & 0.72 & 3.07 & 0.8 & -7.24 & 0.03 & Significant \\
\hline Ability to applying search and meta search engine & 3.02 & 0.94 & 4.50 & 0.9 & -8.76 & 0.04 & Significant \\
\hline
\end{tabular}

SD: Standard deviation. 


\section{Conclusion}

The finding of this study provides considerable evidence that training in online literature search has a marked effect on students' attitude and skills which are vital for the efficient use of online databases.

In terms of the impact of training intervention on students' attitude and their perception toward online literature search, the data shows a significant change after the intervention. This finding is in line with the findings of several studies reporting improvement in student's perception and the performance after training $[5,6,7,8,9]$.

Concerning the impact of training intervention on students' familiarity with medical resources and databases, the results of paired samples test indicated a significant improvement after the intervention. Likewise, Ren [6], Kroustallaki et al. [10] found that training had a significant impact on users' familiarity with resources and databases [7]. Therefore, training intervention and information skills training are worthwhile and effective methods to efficient use of information and resources, provided students put skills into practice.

Regarding the impact of training on students' ability to develop search strategies, Table 2 shows significant improvement after training. This finding supports the findings of Ghali et al. [4], Eldredge et al. [8], and Kroustallaki et al. [10] reporting training had direct and significant effect on users' ability of query formulation and information selection.

Finally, concerning the impact of training intervention on students' ability in applying search and meta search engine, the results showed a significant change in students' skills. Students' ability in performing efficient search engine selection, using Boolean logic operator, and applying search strategies based on search engines tips improved significantly after training. Similarly, Ghali et al. [4] and Gruppen et al. [3] found that training had direct and significant impact on users' ability in applying search and meta search engine.

Although the findings of this study adds to the literature in supporting the role of training in improving students' attitude and skills, the limited number of participants, and students' self-reported behavior changes are the limitations of the study.

In conclusion, our study suggests that training is an effective method for delivering information literacy skills to students and has a significant impact on students' competency in efficient use of online resources. The results of this study showed students' attitude toward online literature searching, their familiarity with medical resources and databases, their ability in developing search strategy and applying search and meta search engine significantly improved after the intervention providing them a great opportunity to practice search skills and improve health care services on the ground of evidence based medicine.

\section{ORCID:}

Mohammadhiwa Abdekhoda: http://orcid.org/0000-0001-9874-3045; Afsaneh Dehnad: http://orcid.org/0000-0001-5731-8894;

Mahmood Yousefi: http://orcid.org/0000-0003-3406-5040

Acknowledgements: None.

Funding: This study was funded by a grant from Tabriz University of Medical Sciences.

Conflicts of interest: None.

\section{References}

1. Abdekhoda M, Dibaj K. Medical librarians and new web technologies: how familiar are we with web facilities and 
use of library services applications? J Health Inform Dev Ctries 2011; 5: 38-46.

2. Gross M, Latham D. What's skill got to do with it?: information literacy skills and self-views of ability among first-year college students. J Assoc Inf Sci Technol 2012; 63: $574-583$.

3. Gruppen LD, Rana GK, Arndt TS. A controlled comparison study of the efficacy of training medical students in evidence-based medicine literature searching skills. Acad Med 2005; 80: 940-944.

4. Ghali WA, Saitz R, Eskew AH, Gupta M, Quan H, Hershman WY. Successful teaching in evidence-based medicine. Med Educ 2000; 34: 18-22.

5. Rosenberg WM, Deeks J, Lusher A, Snowball R, Dooley G, Sackett D. Improving searching skills and evidence retrieval. J R Coll Physicians Lond 1998; 32: 557-563.

6. Ren WH. Library instruction and college student selfefficacy in electronic information searching. J Acad
Librariansh 2000; 26: 323-328.

7. Ilic D, Tepper K, Misso M. Teaching evidence-based medicine literature searching skills to medical students during the clinical years: a randomized controlled trial. J Med Libr Assoc 2012; 100: 190-196.

8. Eldredge JD, Bear DG, Wayne SJ, Perea PP. Student peer assessment in evidence-based medicine (EBM) searching skills training: an experiment. J Med Libr Assoc 2013; 101: 244-251.

9. Qureshi A, Bokhari SA, Pirvani M, Dawani N. Understanding and practice of evidence based search strategy among postgraduate dental students: a preliminary study. J Evid Based Dent Pract 2015; 15: 44-49.

10. Kroustallaki D, Kokkinaki T, Sideridis GD, Simos PG. Exploring students' affect and achievement goals in the context of an intervention to improve web searching skills. Comput Human Behav 2015; 49: 156-170. 